\title{
Management of the deep carious lesion and the vital pulp dentine complex
}

\author{
D. Ricketts, '
}

\begin{abstract}
This article describes the relationship between the carious process and pulp-dentine complex reactions. Where the balance between the two is in favour of the carious process and where conventional cavity preparation leads to a direct pulp exposure, the direct pulp cap technique is described. The success of the technique is addressed and more importantly an alternative technique for caries removal, namely stepwise excavation, is described which may lead to a reduced risk of carious exposure and the need for the direct pulp cap technique.
\end{abstract}

$\mathrm{T}$ rauma, rapidly progressing caries or over zealous removal of caries can result in exposure of the dental pulp. In these situations a direct pulp capping technique can be considered in an attempt to preserve the vitality of the pulp and to stimulate it to produce a calcific barrier to wall off the exposure. However, the health of the pulp and its healing capacity will depend on a number of factors, including the precipitating event leading to the exposure.

Following trauma, when a previously sound, asymptomatic tooth suffers a coronal fracture involving the pulp, it is widely accepted that the direct pulp cap is the treatment of choice, providing the exposure is small and is treated within 24 hours. ${ }^{1,2,3}$ In this situation the depth of damage to the pulp tissue is small and the relatively healthy pulp tissue has considerable reparative potential, particularly in young teeth with immature apices and a good blood supply. However, the caries process can lead to marked changes within the pulp-dentine complex, which can vary considerably depending on the severity of the disease and the age of the pulp. Where deep dentine

${ }^{1}$ Clinical Lecturer, Unit of Comprehensive Restorative Care, Dundee Dental Hospital, Park Place, Dundee DD1 4 HR

*Correspondence to: David Ricketts email:d.n.j.ricketts@dundee.ac.uk

REFEREED PAPER

Received 27.02.01; Accepted 16.07.01

(c) British Dental Journal 2001; 191: 606-610 lesions are concerned it is currently taught that the peripheral aspect of the cavity should be rendered completely caries free. This should be followed by careful excavation of caries at the base of the cavity, overlying the pulp until hard, stained dentine is reached, ${ }^{4}$ thus gradually reducing the bacterial load within the cavity. If at final excavation the pulp is exposed, the possibility of a direct pulp cap can be evaluated.

\section{In brief \\ - The direct pulp cap, whilst predictable for the traumatically exposed pulp, has a questionable long term prognosis where a carious exposure is concerned \\ - The activity of a deep carious lesion in dentine can be preferentially modified, by sealing in the dentine caries. This allows reparative pulp- dentine complex reactions to take place \\ - When such lesions are re-entered after six months or more the risks of directly exposing the pulp are reduced}

Whilst the literature is replete with studies on caries and endodontic procedures, relatively little has been published on the relationship between caries and the vital pulp-dentine complex. This article therefore aims to review the literature on pulpdentine complex reactions to caries and the direct pulp capping technique. It will also aim to address when to place a direct pulp cap and when to undertake root canal treatment, what materials to use and the longterm prognosis of such a procedure. More importantly, an alternative technique of caries removal will be discussed which has been shown to reduce the risk of pulpal exposure.

\section{Dental caries and the pulp dentine complex reactions}

Dental caries in enamel is a subsurface demineralisation caused by acids produced by bacteria in the surface plaque. These acids diffuse into the tooth structure causing demineralisation. It is only when the relatively more mineralised surface zone breaks down that bacteria colonize the enamel lesion. At this early stage in the carious process there is some disagreement as to when the first pulp-dentine complex reactions occur. Brännström and Lind $(1965)^{5}$ for example, found an increase in chronic inflammatory cells beneath lesions apparently confined to enamel, whereas others report that this only occurs when caries extends into dentine. ${ }^{6}$

At the advancing front of a dentine lesion, demineralisation also precedes bacterial invasion. Considerable demineralisation of dentine occurs prior to bacterial infection ${ }^{7}$ and where occlusal lesions are concerned it is only when the caries extends into the middle third of dentine and is radiographically visible that significant infection of the dentine occurs. ${ }^{8}$ Fuzayama investigated the relationship between dentine softening, discolouration and bacterial infection and found that softening preceded discolouration which in turn preceded bacterial invasion. ${ }^{9}$ Thus bacterial acids and products, such as proteases, diffuse ahead of the bacteria towards the pulp and a number of factors influence the rate at which this occurs. These are namely the concentration of bacterial by-products, the permeability of the dentine and the pulpal fluid pressure. ${ }^{10}$

The frequency of sugar consumption and hence acid provoking attacks will affect the 
concentration of acid produced in the dental plaque. This in turn will be moderated to some extent by saliva or whether the lesion is open (frank cavitation) or closed, but in general the more acid produced the greater the concentration gradient toward the pulp.

The permeability of the dentine, which resists this inward diffusion of acid, changes with age. Newly erupted teeth are more permeable and less mineralised allowing the rapid diffusion of acids. As such they may be more susceptible to rapidly progressing caries. Pulp dentine complex reactions to this stimulus are aimed at reducing the permeability of the dentine. The most common reaction depends upon a vital odontoblast process and is the deposition of apatite and whitlockite crystals within the dentinal tubules leading to dentine tubule sclerosis. In addition to this, tertiary dentine may also be laid down by the odontoblast within the pulp chamber. ${ }^{10}$

If the carious process proceeds unchecked, degenerative changes within the odontoblasts take place before inflammatory changes within the pulp occur. ${ }^{11}$ This can lead to complete cell death and replacement by odontoprogenitor cells from the subjacent cell rich layer. Differentiation of these mesenchymal cells into odontoblastlike cells, can lead to the production of reparative dentine which, depending on the severity of the carious lesion, can be irregular with cellular inclusions or if less aggressive resemble normal tubular dentine.

Thus there is a fine balance between the speed of the advancing front of the dentine lesion and the rate at which pulp-dentine defenses can be laid down. These pulp-dentine reactions require a healthy pulp, however if the carious process continues unchecked pulpal inflammation will ensue. In an attempt to evaluate the relationship between lesion depth and pulpal inflammation, Reeves and Stanley (1966) showed that if the advancing front of the lesion was about $1 \mathrm{~mm}$ from the pulp then no significant disturbance occurred. ${ }^{12}$ However, once within $0.5 \mathrm{~mm}$ of the pulp more pathological changes occur, but it was only when the reactionary dentine itself was involved that 'pathosis of real consequence' was seen. Shovelton also showed that it was only when the lesion was within $0.25 \mathrm{~mm}-0.3 \mathrm{~mm}$ of the pulp that hyperaemia and pulpitis occurred. ${ }^{7}$

Thus in final excavation of soft pulpal caries, if direct perforation of the pulp occurs the relative rate of progression of the lesion has been faster than the rate of pulp-dentine reactions. At this stage the pulp is likely to be inflamed and the decision of whether to place a direct pulp cap has to be made.

\section{The direct pulp cap.}

A direct pulp cap usually involves the placement of a calcium hydroxide preparation directly in contact with an exposed pulp. For a direct pulp cap to be successful a number of factors have to be met and these are detailed in Table 1. Lin and Langland (1981) have shown that teeth with a history of pain will have an area of necrosis within the pulp chamber and for many this will extend into the root canal. ${ }^{13}$ Bacterial invasion of pulp tissue is closely related to this necrosis and as such these teeth should be endodontically treated. Teeth exposed during caries removal will inevitably have some degree of inflammation although the histological extent of this cannot be accurately predicted from a clinical examination. Table 1 provides sensible but not infallible clinical criteria for successful direct pulp capping.

It was once thought that only pinpoint exposures could be pulp capped, however more recent research would suggest that the size of exposure has no bearing on clinical outcome. ${ }^{14,15,16}$ Whilst these studies pertain to traumatically exposed pulps, Mejare and Cvek (1993) have suggested that deep carious exposures be opened up so that $1 \mathrm{~mm}-3 \mathrm{~mm}$ of exposed pulp can be removed. ${ }^{17}$ It is important to draw attention to the fact that this study was on young posterior teeth and cannot be regarded as a true direct pulp cap, but rather a partial pulpotomy. This procedure has a number of advantages; it reduces the potential for introduction of dentine chips into the pulp tissue and it enables good contact between pulp and capping agent. It has been shown that dentine chips inadvertently pushed into the pulp tissue cause severe inflammatory reaction, which can lead to pulp necrosis. ${ }^{18,19}$ It also removes superficially contaminated pulpal tissue.

It is important to emphasize that whilst the size of traumatic exposures is not so important, carious exposures should be small even if they are opened up further at operation. It is generally agreed that larger carious exposures have a poor prognosis due to a more severely inflammed pulp, risk of necrosis and bacterial contamination. ${ }^{20,21,22}$

The issue of age is also difficult, as there is no clear cut-off when a direct pulp cap should no longer be considered. The ageing process is gradual and with increased age the pulp tissue becomes more fibrous with a reduction in pulp volume as a result of physiological secondary dentine formation and reactionary dentine due to external stimuli such as trauma, caries and tooth wear. The blood supply to the dental pulp is critical to its health and regenerative capacity, and as this decreases with age so does its capacity to respond to a direct pulp cap. Hence rather than a chronological age as a cut-off, the biological age of an individual tooth should be assessed and a previous restorative history taken into consideration as well as the factors in Table 1.

Table I Criteria essential for a successful direct pulp cap.

\begin{tabular}{|c|c|c|}
\hline History & Preoperative assessment & Clinical findings. \\
\hline $\begin{array}{l}\text { No recurring or } \\
\text { spontaneous pain. } \\
\text { No swelling. }\end{array}$ & $\begin{array}{l}\text { Normal vitality tests. } \\
\text { Not tender to percussion. } \\
\text { No radiographic evidence } \\
\text { of periradicular pathology. } \\
\text { Young patient. } \\
\text { Radiographically obvious } \\
\text { pulp chamber and root canal. }\end{array}$ & $\begin{array}{l}\text { Pink pulp } \\
\text { Bleed if touched but not } \\
\text { excessively. }\end{array}$ \\
\hline
\end{tabular}


Finally the location of the exposure is important as there should be no pulp tissue coronal to the exposure. Exposure in a cervical cavity would lead to reactionary dentine formation which would restrict the blood supply to the tissue more coronal to it, leading to necrosis and failure. These teeth should therefore be root treated. ${ }^{23}$

Calcium hydroxide to date remains the material of choice for a direct pulp capping technique in general practice. Its properties and mode of action have been comprehensively reviewed previously. ${ }^{24}$ However, a relatively new material, mineral trioxide aggregate (MTA) has been investigated. ${ }^{25}$ It consists of fine hydrophilic particles, which when mixed with sterile water results in a colloidal gel of $\mathrm{pH}$ 12.5. This gel solidifies to a hard structure within approximately 4 hours. Once set, it has a high compressive strength comparable to IRM or Super EBA. Both laboratory and clinical studies have shown this material to be extremely biocompatable with pulp tissue and to have good sealing ability against dyes and bacteria. In a limited study, Pitt-Ford et al., showed that direct pulpal exposures treated with MTA demonstrated more predictable dentine bridge formation than calcium hydroxide. ${ }^{26}$ It would therefore appear that this material may be the material of choice for future pulp caps. However, problems associated with the material's difficult handling properties and prolonged setting time may preclude its widespread acceptance despite its superior therapeutic properties.

\section{What is the success rate of the pulp cap technique?}

The success rate of a direct pulp cap is difficult to establish from the dental literature as studies fail to clearly identify whether exposures were due to trauma or caries $^{27}$ or address those resulting from trauma only. ${ }^{28}$ Whilst the prognosis of teeth that have received direct pulp caps as a result of trauma would appear good ${ }^{28}$ those with a carious exposure fare less well. ${ }^{29}$ In a retrospective study of 123 direct pulp caps on carious exposures only $37 \%$ were clearly successful after 5 years and after 10 years $80 \%$ had failed. ${ }^{29}$ Loss of pulp vitality in these teeth poses a problem as a significant amount of physiological secondary and reactionary dentine would have developed which has the potential to complicate subsequent root canal treatment. In addition the root canal system may have become infected and prognosis for root treatment is less favorable than if vital pulp tissue were removed. ${ }^{30}$ These results question the success of the direct pulp cap for carious exposures. However, a further thorough audit is required, as only 123 out of a possible 401 teeth with a direct pulp cap were available for 10 year follow up. ${ }^{29}$

\section{The indirect pulp cap.}

When caries is thought to extend close to, or into the pulp, excavation of the pulpal caries can be stopped at stained but firm dentine. ${ }^{31}$ Calcium hydroxide lining is applied over the pulpal dentine prior to placement of the definitive restoration. This is classically referred to as the indirect pulp cap. The difficulty with this technique is knowing how rapid the carious process has been, how much tertiary dentine has been formed and knowing exactly when to stop excavating to avoid pulp exposure. Using a stepwise approach to caries removal these parameters can be regulated with a more predictable outcome.

\section{Stepwise excavation.}

It could be argued that in the absence of any signs and symptoms of pulpitis, and where the criteria in Table 1 are met, it is over-judicious removal of caries that leads to a pulpal exposure. In the majority of cases this can be avoided if a stepwise approach to caries removal is adopted. This approach which is not completely new, ${ }^{32}$ has recently been the subject of renewed interest. Bjørndal et al. $(1997)^{33}$ investigated 31 teeth with gross caries, which from a clinical and radiographic examination were thought to have carious pulpal exposures. In these teeth caries removal was staged over two separate appointments 6-12 months apart. At the first appointment, access to the caries was gained and the periphery of the cavity made completely caries free. Soft, wet and pale coloured dentine was left pulpally, which has previously been shown to be heavily infected. ${ }^{34}$ The cavity was lined with cal- cium hydroxide and restored with glass ionomer and left for 6-12 months.

After this period, cavities were re-entered and the dentine in all teeth was found to be darker in colour, harder and drier in consistency. Microbiological analysis also showed a significant reduction in cultivable microorganisms over the period in which the provisional restorations were in place. These findings would imply that by removing some of the carious biomass and sealing the remaining caries from extrinsic substrate and oral bacteria, the caries left behind after the first excavation had become less active. This allows time for pulp-dentine complex reactions to take place so that at the second excavation visit, there is less likelihood of pulpal exposure. It has also been suggested that by changing the cavity environment from an active lesion into the condition of a more slowly progressing lesion, this will be accompanied by more regular tubular tertiary dentine formation. The success of this technique has been demonstrated in a randomized controlled study comparing conventional cavity preparation of such lesions with stepwise excavation. ${ }^{35}$ Using the stepwise excavation technique significantly fewer teeth had exposed pulps (17.5\%) compared with conventional caries removal (40\%). These results were echoed in a similar study of deep carious lesions in primary teeth. ${ }^{36}$ In this study 55 teeth were treated with the stepwise excavation technique and 55 control teeth were prepared conventionally. The proportion of teeth where pulpal exposure occurred were $15 \%$ and $53 \%$ respectively. The technique has also been shown to be successful in a practice-based study ${ }^{37}$ where only $5.3 \%$ of pulps were exposed.

\section{Leaving heavily infected caries, the dilemma.}

The thought of leaving heavily infected carious dentine for 6-12 months would seem contrary to teaching in dental schools. It has been taught that when a restoration is placed, the presence and severity of pulpal inflammation is related to the level of bacterial microleakage around the restoration. ${ }^{38-41}$ Thus it would be logical to think that leaving dentine caries which is heavily infected would result in similarly severe pul- 
pal inflammation. However, teeth that have been treated with the stepwise excavation technique do not show any signs or symptoms of pulpitis. The difference here may lie in the fact that in the animal studies investigating the effects of bacterial microleakage, cavities have been prepared in sound teeth. The pulp therefore has not had any opportunity to mount its protective reaction and the presence of bacteria and their by-products are in contact with dentine whose tubules are potentially patent and pulp vulnerable. To the contrary, there is now a significant amount of evidence to support the fact that there are few adverse effects, and potential benefits when caries is 'sealed into' a tooth. These studies can be divided into those where caries has been 'sealed in' with a simple fissure sealant and those where ultraconservative caries removal has been followed by placement of a composite restoration over active caries.

\section{Fissure sealant studies.}

When occlusal caries is visible radiographically, the lesion extends into the middle third of dentine ${ }^{42}$ and is heavily infected. ${ }^{8}$ Studies have shown that when a fissure sealant is placed over such lesions there is a significant reduction in the number of cultivable microorganisms. ${ }^{43-48}$ Such lesions appear to arrest and no increase in lesion size has been found radiographically over a period of two years. ${ }^{49}$ In addition no study has reported symptoms of pulpitis or loss of vitality.

\section{Ultraconservative caries removal.}

Perhaps some of the most compelling evidence is provided by Mertz-Fairhurst et al., who in 1998 presented ten year data on 156 ultraconservative, cariostatic sealed restorations. ${ }^{50}$ In this study, teeth with clinical and radiographic evidence of occlusal caries were minimally prepared by placing a $45^{\circ}-60^{\circ}$ bevel in the enamel, surrounding a frankly cavitated lesion. The bevel was at least $1 \mathrm{~mm}$ wide and placed in sound enamel. No attempt was made to remove any carious dentine and the resultant 'cavities' were restored with acid etched composites and covered with fissure sealant. Although a number of these teeth have been lost from the study due to patients failing to return for recall, 85 have been followed throughout the ten years. Various progress reports on the study sample have shown that sealing caries into the tooth arrests the progress of the lesion by effectively eliminating the oral source of substrate to the bacteria within the lesion. ${ }^{51-55}$ Only one restoration appeared to 'cave-in', only one succumbed to secondary caries and 3.5\% showed signs of wear. All the teeth remained symptomless with no signs of pulpal inflammation or necrosis. ${ }^{50}$

\section{Why re-enter?}

The success of this technique is dependent upon the integrity of the restoration and its seal. Regular recall would be essential. In the Mertz-Fairhurst et al. study (1998) the regular recall would identify any lost restoration at an early stage. However, over the ten year period between $18 \%$ and $45 \%$ of patients failed to attend for annual recall. ${ }^{50}$ In the unlikely event that the restoration should fail and not be detected, the potentially reactivated lesion would already be in an advance stage. Following sealing caries into the tooth, the carious dentine becomes dry, harder and darker in colour. ${ }^{33}$ As a result there is shrinkage of the tissue leaving a void beneath the restoration. These two factors support the second stage of the stepwise excavation. However, the work by MertzFairhurst et al. $(1998)^{50}$ would suggest that the interval between first and second excavation is not critical and could be left for considerably longer than 6-12 months.

Thus use of a more conservative technique for removing caries in a young patient with very deep lesions could eliminate the need for the conventional direct pulp cap technique. In those rare instances when this is still required, adoption of the stepwise excavation technique should result in a minimally inflamed pulp, superior tertiary dentine formation, less bacterial load and a more predictable pulp cap. Where this is required the use of calcium hydroxide, whilst acceptable at present, may become superceded by a mineral trioxide aggregate material.

\section{Conclusion}

These are exciting times when the conventional wisdom of caries removal is being challenged. ${ }^{56}$ This together with the evolu- tion of new dental materials, demand further research into this subject, particularly where older more compromised teeth are concerned.

1 Cox C F, Bergenholtz G, Heys D R, Syed A, Fitzgerald M, Heys J R. Pulp capping of dental pulp mechanically exposed to oral microflora: a 1-2 year observation of wound healing in monkey. J Oral Pathol 1985; 14: 156-168.

2 Heidi S, Kerekes K. Delayed direct pulp capping in permanent incisors of monkeys. Int Endo J 1987; 20: 65-74.

3 Pitt Ford T R, Roberts G J. Immediate and delayed direct pulp capping with the use of a new visible light-cured calcium hydroxide preparation. Oral Surg Oral Med Oral Pathol 1991; 71: 338-342.

4 Kidd E A M, Smith B G N. Pickard's Manual of Operative Dentistry. 7th Edition pp 58-59. Oxford: Oxford University Press; 1996.

5 Brännström M, Lind P O. Pulpal response to early dental caries. J Dent Res 1965; 44: 1045-1050.

6 Massler M. Pulpal reaction to dentinal caries. Int Dent J 1967; 17: 441-460.

7 Shovelton D S. A study of deep carious dentine. Int Dent J 1968; 18: 392-405.

8 Ricketts D N J, Kidd E A M, Beighton D. Operative and microbiological validation of visual, radiographic and electronic diagnosis of occlusal caries in non-cavitated teeth judged to be in need of operative care. Br Dent J 1995; 179: 214-220.

9 Fuzayama T, Okuse K, Hosoda H. Relationship between hardness, discoloration and microbial invasion in carious dentin. J Dent Res 1966; 45: 1033-1046.

10 Kim S, Trowbridge H O. Pulpal reaction to caries and dental procedures. In Cohen S, Burns R C, Rudolph P. (eds) Pathways of the pulp. 7th Ed. pp532-534. Missouri: Mosby Inc; 1998.

11 Trowbridge H O. Pathogenesis of pulpitis resulting from dental caries. J Endod 1981; 7: 52-60.

12 Reeves R, Stanley H R. The relationship of bacterial penetration and pulpal pathosis in carious teeth. Oral Surg 1966; 22: 59-65.

13 Lin L, Langeland K. Light and electron microscopic study of teeth with carious pulp exposures. Oral Surg 1981; 51: 292-316.

14 Fuks A B, Cosack A, Klein H, Eidelman E. Partial pulpotomy as a treatment alternative for exposed pulps in crown-fractured permanent incisors. Endodont Dent Traumatol 1987; 3: 100-102.

15 Heide S, Kerekes K. Delayed partial pulpotomy in permanent incisors of monkeys. Int Endodont J 1986; 19: 78-89.

16 Klein H, Fuks A, Eidelman E, Chosack A. Partial pulpotomy following complicated crown fracture in permanent incisors: a clinical and radiographic study. J Pedodont 1985; 9: 142-147. 
17 Mejare I, Cvek M. Partial pulpotomy in young permanent teeth with deep carious lesions. Endodont Dent Traumatol 1993; 9: 238-242.

18 Kalins V, Frisbie H E. Effect of dentine fragments on the healing of the exposed pulp. Arch Oral Biol 1960; 2: 96-103.

19 Mjör I A, Dahl E, Cox C F. Healing of pulp exposures: an ultrastructural study. J Oral Pathol Med 1991; 20: 496-501.

20 Dannenberg J L. Pedodontic-endodontics. Dent Clin North Am 1974; 18: 367-377.

21 McDonald R E, Avery D R. Treatment of deep caries, vital pulp exposure, and pulpless teeth in children. In McDonald R E, Avery D R, (eds). Dentistry for the child and adolescent. 3rd ed. St Louis: Mosby, 1978.

22 Seltzer S, Bender I B. Pulp capping and pulpotomy. In Seltzer S, Bender I B (eds). The dental pulp, biologic considerations in dental procedures. 2nd ed. Philadelphia: Jb Lippincott, 1975.

23 Stanley H R, Lundy T. Dycal therapy for pulp exposure. Oral Surg Oral Med Oral Pathol. 1972; 34: 818-827.

24 Forman P C, Barnes I E. A review of calcium hydroxide. Int Endod J 1990; 23: 283-297.

25 Torabinejad M, Chivian N. Clinical applications of mineral trioxide aggregate. JEndodon 1999; 25: 197-205.

26 Pitt Ford T R, Torabinejad M, Abedi H R, Bakland L K, Kariyawasam S P. Using mineral trioxide aggregate as a pulp-capping material. J Am Dent Assoc 1996; 127: 1491-1494.

27 Armstrong W P, Hoffman S. Pulp cap study. Oral Surg Oral Med Oral Pathol. 1965; 15: 1505-1509.

28 Cvek M. A clinical report on partial pulpotomy and capping with calcium hydroxide in permanent incisors with complicated crown fracture. JEndodon 1978; 4: 232-242.

29 Barthel C R, Rosenkranz B, Leuenberg A, Roulet J-F. Pulp capping of carious exposures: treatment outcome after 5 and 10 years: a retrospective study. J Endodon 2000; 26: 525-528.

30 Sjögren U, Hagglund B, Sundqvist G, Wing K. Factors affecting long term results of endodontic treatment. J Endodon 1990; 16: 498-504.

31 Kidd E A M, Smith B G N. Pickard's Manual of Operative Dentistry. 7th Edition p 59. Oxford: Oxford University Press; 1996.
32 King J B, Crawford J J, Lindahl R L. Indirect pulp capping: a bacteriologic study of deep carious dentine in human teeth. Oral Surg Oral Med Oral Pathol 1965; 20: 663-671.

33 Bjørndal L, Larsen T, Thylstrup A. A clinical and microbiological study of deep carious lesions during stepwise excavation using long treatment intervals. Caries Res 1997; 31: 411-417.

34 Kidd E A M, Ricketts D N J, Beighton D. Criteria for caries removal at the ename dentine junction: a clinical and microbiological study. Br Dent J 1996; 180: 287-291.

35 Leksell E, Ridell K, Cvek M, Mejare I. Pulp exposure after stepwise versus direct complete excavation of deep carious lesions in young posterior permanent teeth. Endod Dent Traumatol 1996; 12: 192-196.

36 Magnusson B O, Sundell S O. Stepwise excavation of deep carious lesions in primary molars. J Int Ass Dent Child 1977; 8: 36-40.

37 Bjørndal L, Thylstrup A. A practice-based study on stepwise excavation of deep carious lesions in permanent teeth: a 1 year follow-up study. Community Dent Oral Epidemiol. 1998; 26: $122-128$.

38 Bergenholtz G, Cox C F, Loesche W J, Syed S A. Bacterial leakage around dental restorations: its effect on the dental pulp. J Oral Pathol 1982; 11: 439-450.

39 Cox C F, Keall C L, Keall H J, Ostro E, Bergenholtz G. Biocompatibility of surfacesealed dental materials against exposed pulps. J Pros Dent 1987; 57: 1-8.

40 Cox C F, Sübay R K, Suzuki S, Suzuki S H, Ostro E. Biocompatability of various dental materials: pulp healing with a surface seal. Int J Periodont Rest Dent 1996; 16: 241-251.

41 Grieve A R, Alani A, Saunders W P. The effects on the dental pulp of a composite resin and two dentine bonding agents and associated bacterial microleakage. Int Endod J 1991; 24: 108-118.

42 Ricketts D N J, Kidd E A M, Smith B G N, Wilson R F. Clinical and radiographic diagnosis of occlusal caries: a study in vitro. J Oral Rehabil 1995; 22: 15-20.

43 Handelman S L, Buonocore M G, Heseck D J. A preliminary report on the effect of fissure sealant on bacteria in dental caries. J Prosthet Dent 1972; 27: 390-392.

44 Handelman S L, Buonocore M G, Schoute P C.
Progress report on the effect of a fissure sealant in dental caries. J Am Dent Assoc 1973; 87: 1189-1191.

45 Handelman S L, Wasburn F, Wopperer P. Two-year report of sealant effect on bacteria in dental caries. J Am Dent Assoc 1976; 93: 967-970.

46 Going R E, Loesche W J, Grainger D A, Syed S A. The viability of micro-organisms in carious lesions five years after covering with a fissure sealant. J Am Dent Assoc 1978; 97: 455-462.

47 Jensen O E, Handelman S L. Effect of an autopolymerising sealant on viability of microflora in occlusal dental caries. Scand J Dent Res 1980; 88: 382-388.

48 Mertz-Fairhurst E J, Schuster G S, Fairhurst C W. Arresting caries by sealants: results of a clinical study. J Am Dent Assoc 1986; 112 : 194-197.

49 Handelman S L, Leverett D H, Espeland M A, Curzon J A. Clinical radiographic evaluation of sealed carious and sound tooth surfaces. J Am Dent Assoc 1986; 113: 751-754.

50 Mertz-Fairhurst E J, Curtis J W, Ergle J W, Rueggeberg F A, Adair S M. Ultraconservative and cariostatic sealed restorations: results at year 10. J Am Dent Assoc 1998; 129: 55-66.

51 Mertz-Fairhurst E J, Call-Smith K M, Schuster G S, et al. Clinical performance of sealed composite restorations placed over caries compared with sealed and unsealed amalgam restorations. J Am Dent Assoc 1987; 115: 689-694.

52 Mertz-Fairhurst E J, Williams J E, Schustre G S, et al. Ultraconservative sealed restorations: three-year results. J Public Health Dent 1991; 51:239-50.

53 Mertz-Fairhurst E J, Williams J E, Pierce K L, et al. Sealed restorations: 5 year results. $A m \mathrm{~J}$ Dent 1992; 5: 5-10.

54 Mertz-Fairhurst E J, Smith C D, Williams J E, et al. Cariostatic and ultraconservative sealed restorations: six year results. Quintessence Int 1992; 23: 827-838.

55 Mertz-Fairhurst E J, Adair S M, Sams D R, et al. Cariostatic and ultraconservative sealed restorations: nine-year results among children and adults. ASDC J Dent Child 1995; 62: 97-106.

56 Kidd E. Caries removal and the pulpo-dentinal complex. Dent Update 2000; 27; 476-482. 